\title{
SOBRE LA CORRECTA INTERPRETACIÓ DELS FONEMES VOCÀLICS DE L'ALGUERÈS: UN ESTUDI ACÚSTIC*
}

\author{
ON THE CORRECT INTERPRETATION OF VOWEL \\ PHONEMES IN ALGHERESE CATALAN: \\ AN ACOUSTIC STUDY
}

\author{
Francesc Ballone \\ Universitat Autònoma de Barcelona \\ francesco.ballone@libero.it
}

Resum: En els treballs de dialectologia catalana són sovent presents errors en la interpretació dels fonemes vocàlics del català de l'Alguer, i especialment dels fonemes mitjans /e, $\varepsilon, 0$, o/. L'objectiu principal d'aquest estudi és d'avaluar instrumentalment el rol que la distribució al-lofónica de les vocals tòniques en l'espai vocàlic pot jugar en augmentar el risc de no interpretar correctament els fonemes algueresos per part de locutors d'altres àrees dialectals del domini lingüístic català. Les dades obtengudes indiquen que és suposable una correlació entre diferències acústiques dialectals i errades interpretacions dels fonemes vocàlics de l'alguerès per part d'estudiosos catalanoparlants no algueresos. Per exemple, una certa tendència a interpretar les vocals mitjanes obertes de l'alguerès com a mitjanes tancades pot ésser atribuïda (entre d'altres possibles factors) a llur realització perceptiblement més alta respecte a les corresponents en quasi totes les altres varietats considerades.

Paraules clau: alguerès, català, vocals, fonètica segmental, fonologia, escala Bark.

Abstract: Research on the Catalan dialects, often include mistakes in the interpretation of the Algherese vowel phonemes, and especially of the mid vowels /e, $\varepsilon, 0, o /$. The main goal of this study is to instrumentally evaluate the role played by the allophonic distribution of stressed vowels in the vowel space in increasing the risk of the misinterpretation of Algherese vowels by other Catalan speakers.

As a result, the data obtained suggest a correlation between dialectal acoustic differences and the incorrect interpretation of Algherese vowel phonemes by non-Algherese scholars. For example, a tendency to interpret open-mid Algherese vowels as close-mid can be attributed (among other 
FranCESC BALlone

Sobre la correcta interpretació dels fonemes vocàlics de l'alguerès: un estudi acústic

factors) to their realisation as perceptively higher than the corresponding ones in almost all the other varieties analysed in this study.

Key words: Algherese, Catalan, vowels, segmental phonetics, phonology, Bark scale.

\section{$\cos \cos$}

\section{OBJECTIUS DE L'ESTUDI}

En els treballs de dialectologia catalana són sovent presents errors en la interpretació dels fonemes vocàlics del català de l'Alguer, i especialment de /e, $\varepsilon, 0$, o/. L'objectiu principal d'aquest estudi és comprendre, utilitzant un enfocament instrumental, si aquests errors poden ésser atribuïbles a diferències acústiques entre les vocals tòniques alguereses i les vocals corresponents en altres varietats del català.

El $\$$ I inclou exemples d'errada classificació foneticofonològica de les vocals alguereses presents en literatura; en el $\$ 2$ se discuteixen unes primeres dades instrumentals relatives a la comparació acústica de vocals alguereses amb les d'altres varietats catalanes; el $\$ 3$ presenta el protocol experimental. Els resultats de l'anàlisi se comenten en el $\$ 4$, i el $\$ 5$ se dedica a les conclusions generals.

\section{INTRODUCCIÓ}

Aquest treball constitueix l'aprofundiment d'un tema ja tractat en Ballone 2008, en el qual s'intentava trobar una explicació de tipus acusticoperceptiu a les nombroses discrepàncies presents en literatura sobre la interpretació dels fonemes vocàlics de l'alguerès. Per exemple Kuen (1932: 138, nota 3) dissenteix amb Alcover quan aquest darrer «escribe ę en anę l, bę l, pę l, vę l, pręsak, ${ }^{2}$ donde ciertamente se pronuncia ẹ cerrada» en alguerès. En la mateixa pàgina, Kuen defineix la vocal anterior mitjana alta d'aquest

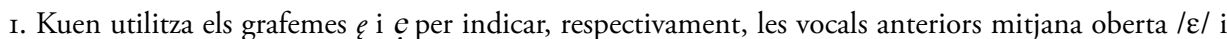
mitjana tancada /e/. Els mateixos diacrítics relatius al grau d'obertura vocàlica són també utilitzats a la base del grafema $o$ per indicar $/ \mathrm{o} / \mathrm{i} / \mathrm{o} /$, respectivament.

2. Les transcripcions corresponen als mots anell, bell, pell, vell, préssec. Kuen treu aquests exemples del Bolleti del Diccionari de la Llengua Catalana, volum XI, I920, p. I8 (<http://taller.iec.cat/filologica/alcover/ documents/IIBDLC_II.pdf >). 
dialecte com a produïda «algo más atrás que la ẹ toscana i francesa» ([ę]?), sobretot en la parla d'algueresos poc afectats per l'italià, i descriu la corresponent vocal mitjana baixa com a caracteritzada per un «escaso grado de abertura» ([E] ?)). Aquests factors acústics constituirien, segons l'autor, «la causa de que se note en Morosi y Guarnerio y también en Griera una cierta inseguridad en la transcripción de los sonidos e». ${ }^{3}$ En tot cas, també Kuen troba en alguerès alguns «sonidos de $e$ y $o$ cuya condición de abiertos o cerrados no pude determinar con seguridad» (p. 139), i també se li escapen (si bé no tan freqüentment) transcripcions fonètiques de vocals mitjanes alguereses que no serien segurament compartides per parlants natius. ${ }^{4}$ Altres exemples de discordances interpretatives de fonemes vocàlics algueresos són disponibles en Ballone (2008, especialment a $\$$ I.I) i en Manunta (I988).

Recasens (1996) descriu així les vocals mitjanes alguereses:

(I) a. /e/: «sembla menys baixa en català central que no pas [...] en alguerès (Kuen I932-1934); és possible que també sigui especialment centralitzada i posterior en alguerès» (p. 7o);

b. / / /: aquest fonema presenta una variant diatòpica «més tancada que l'anterior [és a dir, la del català central i lleidatà] en pallarès (Coromines 1936) i alguerès (Kuen 1932-I934; enquestes personals)» (p. 8I);

c. / /: en el diasistema català, la vocal mitjana baixa posterior labialitzada és present en una «variant més oberta que la corresponent al català central, en val. (Navarro Tomás i Sanchis Guarner 1934) i en bal. [...]», però també en una variant més tancada respecte a la del català central i lleidatà, pròpia del català nord-occidental i de l'alguerès (p. 130).

Tot i que en Recasens (1996) no és present una descripció específica del fonema mitjà alt posterior labialitzat /o/ de l'alguerès, les informacions presentades aquí damunt pareixen ésser ja suficients per suposar una correlació entre algunes discrepàncies interpretatives presents en literatura sobre la caracterització fonològica de les vocals alguereses $\mathrm{i}$ les diferències qualitatives (acústiques) que les mateixes vocals presenten en el diasistema català. Si nos referim a les consideracions en (Ic) a un nivell merament intuïtiu, és suposable que un enquestador que té com a varietat nativa el català nordoccidental tengui més possibilitats d'interpretar correctament la vocal mitjana baixa posterior labialitzada / $/$ / de l'alguerès que no un enquestador natiu de les Balears, on Catalunya.

3. L'autor fa referència a Morosi (I886), Guarnerio (I886), i a les transcripcions de l'Atlas Lingüistic de

4. Per ex. "pulkệdḍu" (p. I47, que al Diccionari Català de l'Alguer — a partir d'ara: DCA — és transcrit fonèticament amb $[\varepsilon]$; veg. allà «porquedo», petit porc), «ma kólk» (p. I7I, «em colg», pronunciat, però, amb

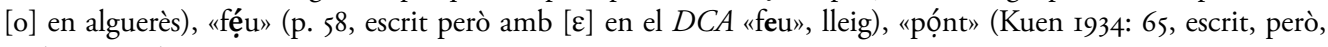
amb [0] en el $D C A$ «pont»).

Caplletra 60 (Primavera, 2016), pp. 55-77 
FranCESC BALLONE

Sobre la correcta interpretació dels fonemes vocàlics de l'alguerès: un estudi acústic

el mateix fonema presentaria un grau d'obertura major. Aquesta possible aplicació pràctica de (Ic) s'ha de considerar òbviament simplista, vist que sabem que la correcta anàlisi impressionista d'un corpus oral pot dependre de molts altres factors, com el nivell de coneixença que un enquestador no natiu té de la varietat considerada, la possibilitat o no de gravar el text oral que se vol estudiar, etc. Tot això considerat, aquesta hipòtesi de base pot començar a ésser posada a prova confrontant exemples de transcripcions relatius a la qualitat de les vocals alguereses.

El primer corpus és tret de l'estudi de Serra (1927), en el qual l'autora algueresa fa una revisió de les primeres 586 fitxes de l'Atlas Lingüistic de Catalunya (ALCat), inserint propostes de modificació a les respostes relatives a l'alguerès. Entre totes les fitxes contengudes en l'estudi de Serra, $43^{5}$ presenten correccions a interpretacions errònies de les vocals tòniques alguereses, així classificables: ${ }^{6}$

\begin{tabular}{|c|c|c|c|c|}
\hline & n. fitxa & pregunta & transcr. Griera & transcr. Serra \\
\hline transcripció de [e] tònica com a [i] (I cas) & 355 & «els cadells» & $\operatorname{cutx}[\mathrm{i}] \mathrm{t}$ & $\operatorname{cutx}[\mathrm{e}] \mathrm{ts}$ \\
\hline \multirow[t]{3}{*}{ transcr. de $[\mathrm{o}]$ tònica com a $[\mathrm{u}]$ (3 casos) } & $2 \mathrm{I}$ & «els afores» & ent $[u] \mathrm{rns}$ & ent $[\mathrm{o}] \mathrm{rns}$ \\
\hline & 323 & «una brossa (a l'ull)» & $\mathrm{p}[\mathrm{u}] \mathrm{ls}$ & $\mathrm{p}[\mathrm{o}] \mathrm{ls}$ \\
\hline & 500 & «el codony» & $\operatorname{cod}[u] n y$ & $\operatorname{cod}[o] n y$ \\
\hline \multirow[t]{3}{*}{ transcr. de $[\varepsilon]$ tònica com a $[\mathrm{e}]$ ( $\mathrm{I} 5$ casos) } & $\mathrm{I} 72$ & «asseure’s» & $s[e]$ ure & $s[\varepsilon]$ ure \\
\hline & 383 & «la candela» & cand $[\mathrm{e}] \mathrm{la}$ & cand $[\varepsilon] \mathrm{la}$ \\
\hline & $\begin{array}{l}454 \\
{[\ldots]^{7}}\end{array}$ & «el cel» & $c[e] l$ & $c[\varepsilon] 1$ \\
\hline
\end{tabular}

5. La suma inclou també un petit nombre d'errors repetits en més fitxes, com per exemple «la closca (de l'ou)», fitxa 496, i «la closca (dels ous)», fitxa 476, amb la vocal tònica del geosinònim alguerès «escorja» (segons la grafia del $D C A$ ) descrita com a mitjana tancada per Griera i com a mitjana oberta per Serra. En un primer moment havíem pensat de no incloure en el recompte els errors repetits, però la presència de vacil-lacions en la transcripció d'una mateixa paraula per part de Griera (com per exemple «mort» amb [o] en la fitxa 354, i amb [0] en la fitxa 400, i encara amb [o] en la fitxa 547) nos han fet preferir de considerar en el recompte cada u dels exemples de discrepància entre les dues transcripcions.

6. Per brevetat, havem inclòs a la taula solament el nombre de la fitxa i la pregunta corresponent de l'ALCat, i, en les respostes (veg. columnes «transcr. Griera» i «transcr. Serra»), solament la paraula que conté el so vocàlic corregit. Igualment, per facilitar la lectura dels exemples reportats, la transcripció ortogràfica dels termes algueresos és estada feta segons els criteris del $D C A$, i la qualitat de la vocal tònica és estada indicada utilitzant els grafemes de l'Alfabet Fonètic Internacional (AFI).

7. Els altres exemples són: fitxa I68 «l'ase, els ases»: mol[e]ndo (Griera), mol[ع]ndo (Serra); 264 «(són)

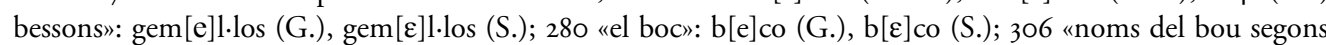


Francesc Ballone

Sobre la correcta interpretació dels fonemes vocàlics de l'alguerès: un estudi acústic

\begin{tabular}{lllll}
\hline transcr. de [0] tònica com a [o] (24 casos) & 326 & «el brou (caldo)» & br[o]u & br[o]u \\
& 508 & «la col» & $c[0] l$ & $c[0] l$ \\
& 546 & «el cos» & $c[0] s$ & $c[0] s$ \\
& {$[\ldots]$} & & & \\
\hline
\end{tabular}

Taula I. presentació tipològica de les correccions de Serra (1927) a les transcripcions de l'A $A$ Cat relatives a paraules alguereses. La taula solament inclou rectificacions referides als sons vocàlics.

Si mirem les correccions de la taula, resulta ben probable que una bona part d'aquestes puguin ésser explicades a partir de les consideracions en (Ib) i (Ic). De fet, en 39 casos sobre 43, sem en presència d'interpretacions errònies de vocals mitjanes; i encara més digne de nota és el fet que sempre se tracta de vocals mitjanes baixes interpretades com a mitjanes altes. ${ }^{9}$ Comença així a resultar difícil creure que, donant per bones les informacions en (Ib) i (Ic), en aquestes interpretacions no hagi jugat cap paper el fet que en alguerès les vocals mitjanes obertes siguin no tan obertes com les del català central (és a dir la varietat de referència de Griera).

Per una altra banda, les transcripcions de l'ALCat suggereixen que si fos demostrable una correlació entre factors acústics i interpretacions errònies de vocals alguereses, aquesta correlació és suposable solament en termes probabilístics, vist que hi pot ésser vacil-lació fins i tot en la interpretació de la mateixa paraula en fitxes diferents (per exemple, «mort», transcrit amb [o] a les fitxes 354 i 547 , i — correcta-

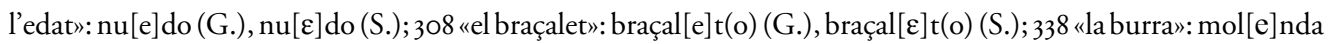

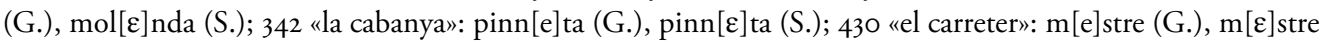

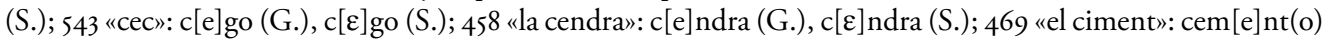
(G.), $\operatorname{cem}[\varepsilon] \mathrm{nt}(\mathrm{o})(\mathrm{S}) ;$.479 «la cisterna»: $\operatorname{cist}[\mathrm{e}] \mathrm{rna}(\mathrm{G}$.$) , \operatorname{cist}[\varepsilon] \mathrm{rna}(\mathrm{S}$.$) .$

8. Seguint els criteris de la nota precedent, llistem aquí els altres exemples: 4I «una airada»: c[o]p (G.), c[0]p (S.); 57 «l'arbecoquer»: barrac[o]c (G.), barrac[0]c (S.); 75 «l'all porrer»: p[o]rro (G.), p[o]rro (S.); 89 «amonestar»: monit[o]ris (G.), monit[0] ris (S.); I39 «l'arbós»: alid[o]ni (G.), alid[0]ni (S.); 2I7 «la banya, les banyes»: c[o] rro (G.), c[0] rro (S.); 218 «(la cabra) banyuda»: c[o] rros (G.), c[0] rros (S.); 279 «bo»: b[o] (G.), b[0] (S.); 284 «la boira»: b[o]ria (G.), b[o]ria (S.); 289 «bona nit»: b[o]na (G.), b[0]na (S.); 290 «bones tardes»: b[o]nes (G.), b[0]nes (S.); 29I «bons dies»: b[o]nes (G.), b[o]nes (S.); 316 «el bressol»: bress[o]l (G.), bress[0]l (S.); 354 "un cadàver, una calavera»: m[o]lt (G.), m[o]lt (S.); 384 «la Candelera»: candel[o] ra (G.), candel[o] ra (S.); 439 «el casament»: espos[o]ri (G.), espos[0]ri (S.); 496 «la closca (de l'ou)»: esc[o]rja (G.), esc[0]rja (S.); 497 «la closca (de les nou)»: esc[o]rja (G.), esc[0]rja (S.); 516 «el coll»: c[o]ll (G.), c[0]ll (S.); 547 «un cos (difunt)»: m[o]lt (G.), m[o]lt (S.); 574 «el cove»: c[o]ve (G.), c[o]ve (S.).

9. Dos exemples contraris, relatius però al domini àton, són la transcripció de la [i] de "cariasa» (cirera) com a «e» (fitxes 476 i 477) i la transcripció de l'article determinatiu [lu] com a «lo» (fitxes I06 i 385 ).

Caplletra 60 (Primavera, 2016), pp. 55-77 
FranCESC BALLONE

Sobre la correcta interpretació dels fonemes vocàlics de l'alguerès: un estudi acuistic

ment- amb [0] a la fitxa 400; i «dosso», escrit amb [o] a la fitxa I54, i correctament amb [0] a la fitxa 559). ${ }^{10}$

Quan avaluem el treball de Griera, no hem d'oblidar les condicions encara pioneres en les quals treballaven els lingüistes d'aquella època, els quals feven investigació de camp normalment sense l'auxili d'enregistradors i en condicions de treball no sempre ideals. ${ }^{11}$ A partir d'aquell període, una nova generació de recercadors ha sabut aprofitar els avantatges aportats per les noves tecnologies d'enregistrament i d'anàlisi, i també la facilitat sempre creixent de poder accedir a les localitats d'indagació. Aquests factors, juntament amb el desenvolupament d'una metodologia d'investigació més rigorosa, ha permès a la dialectologia catalana dels darrers decennis de dotar-se d'un atles de qualitat indiscutible com és l'Atles Lingüistic del Domini Català $(A L D C)$. Del punt de vista de l'autor del present treball, és estat interessant notar que tambél' $A L D C$ presenta transcripcions fonètiques relatives a mots algueresos que pareixen ésser afectades pels factors acústics anticipats en (Ib) i (IC). La taula 2 mostra els casos de transcripcions fonètiques de vocals tòniques alguereses del primer volum de l' $A L D C(A L D C \mathrm{I})$ que presenten discrepàncies amb les transcripcions corresponents en el $D C A .{ }^{12}$

\begin{tabular}{|c|c|}
\hline transcripció $A L D C 2004$ & transcripció $D C A$ \\
\hline puls (f. IO) & $\mathrm{p}[\mathrm{o}] \mathrm{ls}$ \\
\hline ults'ol (f. I7) & $\operatorname{urç}[0] 1$ \\
\hline bj'ondu (f. 29) & bi[0]nd \\
\hline kant'elzus (f. 38) & $\operatorname{cant}[\varepsilon]$ rjos \\
\hline $\operatorname{mos}($ f. 54$)$ & $\mathrm{m}[0] \mathrm{s}$ \\
\hline prum'onis (f. 63) & plum[o]ni \\
\hline
\end{tabular}

Io. Un error ben conegut present en l'apartat alguerès de l'ALC, no atribuïble a factors foneticoperceptius, sinó exclusivament a la metodologia d'investigació, és el de «l'alguamoll» (fitxa 37), que presenta la resposta «l'alğunasain », no perquè aquest mot compost existeixi efectivament en alguerès, sinó a causa d'una probable mala interpretació del terme català per part de l'entrevistat (sobre aquesta possibilitat, veg. també Corbera 2000: 2I). II. A aquest propòsit, al prefaci de Wagner (1997) són presents algunes notícies curioses sobre els primers viatges del lingüista alemany a Sardenya i sobre les dificultats per a arribar a algunes regions aïllades de l'illa.

I2. Sobre l'alt grau de fiabilitat del $D C A$ en les transcripcions fonètiques de les vocals mitjanes alguereses, veg. Ballone (2008). En la taula, la transcripció del $D C A$ és donada en forma ortogràfica, amb l'excepció de la vocal investigada, la qual és presentada en grafia fonètica. Les transcripcions relatives a l' $A L D C$ I són reproduïdes fidelment, inclosa la col-locació de l'accent primari just abans de la vocal tònica, i no (com és més usual en la grafia AFI) abans de l'obertura de la síl-laba tònica (per exemple, s'ha deixat [batik'ol] per [bati'kol]). L'abreviació «f.» se té de llegir «fitxa», i «i.c.» indica que la transcripció se troba en l'apartat «informació complementària». 


\begin{tabular}{|c|c|}
\hline S'ela (f. 65) & aix $[\varepsilon]$ lla \\
\hline k'oddus (f. 8I) & $\mathrm{c}[\mathrm{0}] \mathrm{do}$ \\
\hline amb'osta (f. IO2) & emb[0]sta \\
\hline pirindz'onis (f. IIz) & pirinj $[0] \mathrm{ni}$ \\
\hline bultf'oni, kats'otu (f. II3) & bultx[0] ni, catz[0] to \\
\hline batik'ol (f. II5) & batc $[0] 11$ \\
\hline t''eru (f. I43) & $\operatorname{tx}[\varepsilon] \mathrm{go}$ \\
\hline ma sk'era (f. I46) & esqu $[\varepsilon]$ rra \\
\hline g'obu (f. I50) & $\mathrm{g}[\mathrm{o}] \mathrm{bo}$ \\
\hline g'oba (f. I5I) & $\mathrm{g}[\mathrm{\rho}] \mathrm{ba}$ \\
\hline 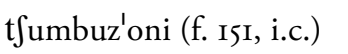 & xumbos[0]ni \\
\hline asforu (f. I6I, i.c.) & esf[0]go \\
\hline mur'endu (f. I68) & $\operatorname{mol}[\varepsilon]$ ndo \\
\hline
\end{tabular}

Taula 2. Llista de les transcripcions fonètiques de l' $A L D C$ I que presenten discrepàncies respecte a les transcripcions corresponents del $D C A$ en relació a la qualitat de les vocals tòniques.

Ja en una ràpida lectura és evident que les taules i i 2 presenten diverses similituds. En primer lloc, els errors de categorització vocàlica concerneixen sobretot les vocals mitjanes, $i$, en segon lloc, sem normalment en presència de vocals mitjanes obertes interpretades com a mitjanes tancades. Aquestes similituds donen més força a la hipòtesi que en els estudis de dialectologia catalana hi ha tipologies d'errors interpretatius de fonemes algueresos que no són totalment casuals. Ampliant l'anàlisi de les transcripcions de l'ALDC I també al domini àton, és possible notar casos de [u] alguereses transcrites com a [o] ([los] per [lus], fitxa I4I), i de [i] transcrites com a [e] ([e $\int_{1}$ ira] per $\left[\mathrm{i}_{1}\right.$ ira $]$, fitxa 35$)$ suggerint que no totes les vocals alguereses serien pronunciades com a més altes respecte a les corresponents en altres varietats.

Relativament a les transcripcions de l' $A L D C$ I és necessari un aclariment ulterior. Si donem per bones les possibilitats descrites en (Ib) i (Ic), segons les quals / $\varepsilon / \mathrm{i}$ /\%/ alguereses serien més tancades respecte a les vocals corresponents d'altres varietats catalanes, no seria igualment impossible suposar que les dues vocals siguin normalment transcrites com a [e] i [o] en l'ALDC I no a causa d'errors interpretatius, sinó perquè el timbre percebut relativament a / $/ /$ i / / és, apunt, mitjà alt. Tal possibilitat, però, implicaria que totes les vocals mitjanes baixes alguereses presents en l'ALDC haurien 
d'ésser escrites fonèticament com a [e] i [o]; al contrari, hi ha diversos casos en els quals són representades (correctament) amb [ع] ([gulgu'ena], fitxa 6I) i [o] ([kor], fitxa 64). Per aquesta raó, les discrepàncies presentades a la taula 2 seran atribuïdes en el present treball a errors interpretatius més que no a la decisió conscient de transcriure $/ \varepsilon / \mathrm{i} / \mathrm{\rho} /$ alguereses sistemàticament com a $[\mathrm{e}] \mathrm{i}[\mathrm{o}]$.

\section{HIPÒTESI DE TREBALL}

En Ballone (2013) s'han encreuat dades instrumentals relatives a les vocals tòniques de quatre varietats catalanes (català central, nord-occidental, valencià $\mathrm{i}$ mallorquí) ${ }^{13}$ amb dades corresponents obtengudes per a l'alguerès. La figura I és una adaptació del gràfic present en aquell mateix estudi (p. I25), i mostra els valors FIx F2 de l'alguerès, amitjanats a través de repeticions, contextos consonàntics i parlants, i de quatre varietats catalanes (central, nord-occidental, valencià i mallorquí) amitjanats a través de repeticions, contextos consonàntics, parlants i dialectes: ${ }^{14}$

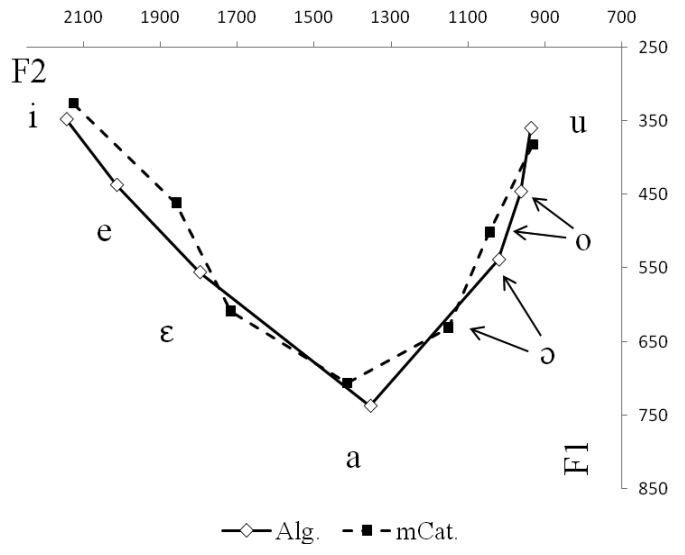

Figura I: representació gràfica dels valors $\mathrm{F}_{\mathrm{x}} \mathrm{F}_{2}$ mitjans, no normalitzats, de les vocals tòniques de l'alguerès (Alg.) i de quatre varietats del català (mCat.).

I3. Aquestes dades s'havien extret de Recasens \& Espinosa (2006).

I4. Respecte al gràfic original, manquen aquí els valors corresponents en quatre varietats de sard. També s'han exclòs, respecte a les dades originals de Recasens \& Espinosa (2006), els valors Fix F2 de la vocal central del mallorquí. 
Les dades mostrades a la figura contradiuen la hipòtesi que /e/ «sigui especialment centralitzada i posterior en alguerès» citada en (Ia), mentre que donarien suport a la possibilitat que les vocals mitjanes alguereses siguin tendencialment més altes respecte al conjunt de les altres quatre varietats catalanes considerades, coherentment amb (Ib) i (Ic). Aquestes consideracions reforçarien la hipòtesi de partida del present estudi, segons la qual la distribució de les vocals mitjanes baixes alguereses en l'espai vocàlic pot haver jugat algun paper a condicionar la interpretació bastant freqüent, en literatura, de / $\varepsilon / \mathrm{i} / \mathrm{\rho} / \mathrm{d}$ 'aquesta varietat com a /e/ i /o/, respectivament, per part d'estudiosos catalanoparlants no algueresos.

\section{METODOLOGIA}

\section{I CORPUS D'INVESTIGACIÓ}

La base de dades utilitzada per a la comparació acústica entre les vocals alguereses i les corresponents en altres varietats de català és treta de Ballone (2013) per a la primera varietat i de Recasens \& Espinosa (2006) per al català central, català nordoccidental, valencià i mallorquí. En els dos treballs el corpus és estat recollit a través de la lectura repetida ${ }^{15} \mathrm{~d}^{\prime}$ un qüestionari lingüístic que presenta les 7 vocals tòniques /i, e, $\varepsilon, \mathrm{a}, \mathrm{\rho}, \mathrm{o}, \mathrm{u} /$ ( $\mathrm{amb}$ l'afegida de /ə/ en mallorquí) en diferents contextos consonàntics. ${ }^{16}$ A aquest primer corpus d'anàlisi s'han afegit també les dades obtengudes —amb una metodologia similar - a Recasens \& Espinosa (2009) relatives al rossellonès i a la subvarietat gironina del català central. En tots els 3 treballs de recerca mencionats suara han participat, com a informants, quatre (rossellonès) o cinc parlants natius (resta de varietats) de cada dialecte considerat, d'edat adulta ${ }^{17}$ i de sexe masculí, per un

I5. Pel que fa als informants de l'Alguer, no s'ha demanat de llegir frases directament escrites en català, vist que la majoria dels algueresos encara no està familiaritzada amb la grafia normativa, sinó se'ls ha demanat de traduir en alguerès unes frases curtes escrites en italià. Relativament al nombre de repeticions, aquestes eren cinc per als informants algueresos i set per a la resta dels informants.

I6. Tals contextos eren labial, palatal i dentoalveolar per al qüestionari de l'alguerès, i labial, palatal, alveolar i $1 / \mathrm{r}$ per a la resta de les varietats. El context $1 / \mathrm{r}$ no és estat considerat per a l'alguerès pels motius descrits en Ballone (2013: 94-95).

17. Algunes diferències d'edat entre els informants algueresos (de 39 a 57 anys) i els informants de les altres varietats de català (de 25 i 45 anys) són degudes a la major dificultat de trobar parlants natius joves en diverses zones de Sardenya, l'Alguer inclòs, on el procés de diglòssia en favor de l'italià és en un estadi molt avançat (veg. Oppo et alii 2007). 
Francesc BALLONE

Sobre la correcta interpretació dels fonemes vocàlics de l'alguerès: un estudi acústic

total de 34 locutors entrevistats i $632 \mathrm{I}^{18}$ vocals analitzades instrumentalment a partir del material enregistrat.

\subsection{ANÀLISI DE LES DADES}

\subsection{Normalització de les dades formàntiques}

Considerant l'enfocament més acusticoperceptiu del present treball, els valors formàntics en $\mathrm{Hz}$ extrets de Ballone (2013) i de Recasens \& Espinosa (2006 i 2009) són estats normalitzats en Bark (Zwicker 196I) segons l'escala de conversió proposada en Traunmüller (I990). ${ }^{19}$

\subsubsection{Avaluació del risc de confusió fonològica en termes d'FIx F2}

En l'avaluació de les diferències acústiques entre les vocals tòniques alguereses i les corresponents en altres varietats catalanes, s' ha donat prioritat a les diferències absolutes en termes d'Fi, d'acord amb Lindblom (I975 i 1986), segons el qual aquest formant se tendria de considerar com el correlat espectral de la intensitat dels sons vocàlics (i per això, amb una importància major respecte a $\mathrm{F}_{2}$ en termes acusticoperceptius), i no solament com el correlat del grau d'obertura vocàlica. Això dit, en l'avaluació del risc de confusió fonològica (RCF) s'ha inclòs també el càlcul de les diferències acústiques en termes d'F2, tal com serà explicat al llarg de la present secció i de $\$$ 3.2.3.

Per explicar el procediment d'avaluació de l'RCF, utilitzarem com a exemple el de la / / / algueresa, una vocal facilment confusible amb /o/ per altres catalanoparlants segons les dades mostrades en la figura I. Posant el cas teòric que la / / / d'una varietat2 del català mesuri $\mathrm{F}_{\mathrm{I}} 6,00 \mathrm{Bark}$, si la vocal corresponent en alguerès presenta un valor Fi Bark més baix (5,70, 5,30, etc.) és suposable que aquesta darrera tengui alguna possibilitat d'ésser confosa amb /o/ per part d'un parlant natiu de la varietat2. S'ha decidit aquí d'establir cinc nivells d'RCF: nul, baix, mitjà, alt, molt alt, utilitzant un mètode percentual calculat sobre la diferència acústica (en aquest cas) entre $/ \mathrm{o} / \mathrm{i}$ /o/ de la varietat2 (nos referirem a aquests fonemes com a /o/2 i /o/2, respectivament,

I8. Aquesta xifra no inclou els mesuraments relatius al sitgetà i al felanitxer publicats a Recasens $\&$ Espinosa (2009), i tampoc els mesuraments relatius a altres experiments publicats a Recasens \& Espinosa (2006) i Ballone (2013).

19. La conversió és estada calculada automàticament mitjançant el programa de conversió disponible a l'adreça electrònica <http://www2.ling.su.se/staff/hartmut/umrechnung.htm> (consulta: O2/03/2OI4). 
en les ratlles següents). A partir d'aquestes premisses, si la Fi de / / / algueresa és més baixa respecte a $/ 0 / 2$ en manera de no superar el $25 \%$ de la distància acústica entre /o/2 i /o/2, l'RCF serà considerat baix; el mateix risc serà considerat mitjà i alt si la distància acústica entre la $/ \mathrm{\rho} /$ algueresa $\mathrm{i} / \mathrm{\rho} / 2$ serà compresa, respectivament, entre $>25-50 \%$ i >50-75\% de la distància entre / $/ 2 / 2$ i /o/2. L'RCF serà considerat molt alt si aquest percentatge supera el $75 \%$ d'aquesta distància. Una simulació gràfica de tal procediment de càlcul d'RCF és presentada a la figura 2.

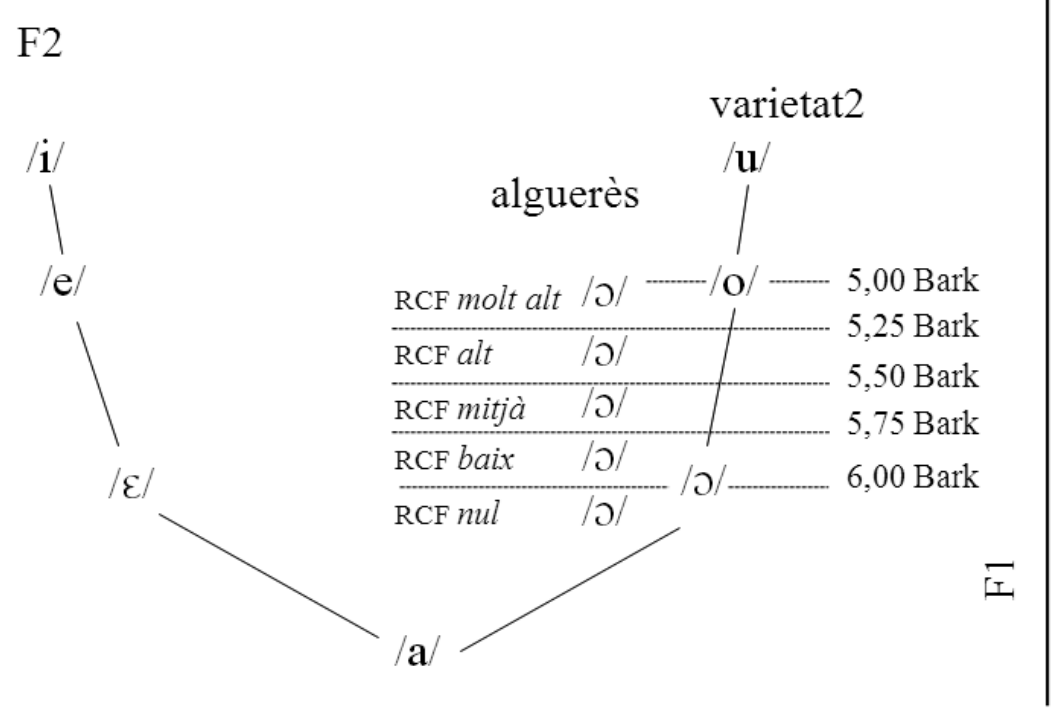

Figura 2. Simulació del càlcul Fi del risc de confusió fonològica relatiu a la / / / algueresa comparada amb la vocal corresponent en una suposada varietat2. Considerant 5,00 i 6,00 Bark, respectivament, el valor de $/ \mathrm{o} / \mathrm{i} / \mathrm{\rho} / \mathrm{de}$ la varietat2, la $/ \mathrm{o} /$ algueresa tendrà un RCF $n u l$ d'ésser confosa amb [o] si el seu valor és $>=6,00$ Bark, un RCF baix si el seu valor és inclòs entre 5,99 i 5,75, un RCF mitjà si és inclòs entre 5,74 i 5,50, un RCF alt si és inclòs entre 5,49 i 5,25, i un RCF molt alt si el valor és inferior a 5,25.

Tal com diu el nom, l'RCF nul serà atribuït a casos on no hi ha cap possibilitat teòrica que factors acústics puguin contribuir a la confusió de fonemes algueresos. Aquest nivell de risc s'aplica a la possibilitat (molt rara, a dir la veritat) que un fonema alguerès coincideixi d'un punt de vista formàntic al corresponent en una altra varietat (per exemple, $/ \mathrm{o} /$ alguerès $=6,00 \mathrm{Bark} \mathrm{i} / \mathrm{\rho} / 2=6,00 \mathrm{Bark}$ ). També s'aplica als casos de /i/ i /u/ alguereses pronunciades més altes, i de /a/ en la mateixa varietat pronunciada més baixa respecte a altres varietats. La motivació d'aquest criteri és intuïtiva: una /a/ algueresa pronunciada més baixa no corre cap risc d'ésser confosa amb altres vocals, i 
FranCESC BALlone

Sobre la correcta interpretació dels fonemes vocàlics de l'alguerès: un estudi acústic

el mateix criteri és aplicable també a /i/i / $/$ / alguereses amb Fi Bark indicatiu d'una articulació especialment elevada. ${ }^{20}$ Un altre cas d'RCF nul és el de la /a/ algueresa que presenti un valor Fi més baix respecte a la vocal corresponent en una altra varietat, $\mathrm{i}$ que no presenti però contemporàniament diferències evidents també en termes de F2. La ràtio d'aquest criteri és que una /a/ especialment alta no corre en realitat cap risc d'ésser confosa amb altres vocals ${ }^{21}$ si no presenta contemporàniament indicadors acústics d'avançament o retracció, i que la farien per això apropar a les zones d'existència de $/ \varepsilon / \mathrm{i} / \mathrm{\rho} /$, respectivament.

El criteri d'avaluació de l'RCF descrit al llarg de la present secció per a Fi s'ha aplicat també a $\mathrm{F}_{2}$, amb una petita modificació. De fet, considerant el rol secundari atribuït a $F_{2}$ respecte a FI en avaluar l'RCF, s'ha decidit de considerar un RCF de F2 com a nul cada volta que aquest formant no ha contribuït a incrementar el risc calculat per FI. Si se pren el cas d'una/i/ algueresa pronunciada com a més baixa respecte a la corresponent en una altra varietat, i el consegüent RCF per a la mateixa vocal d'ésser confosa amb /e/ en termes d'Fi, és evident que aquest risc augmentaria si la /i/ algueresa fos articulada també com a més posterior. No cal dir que si la mateixa vocal és produïda com a més baixa i contemporàniament més anterior, el valor d'F2 no augmentaria el risc de confusió amb /e/, i per això l'RCF causat d'aquest darrer valor s'ha considerat simplement $n u l$. En tal sentit, el rol primari atribuït a FI respecte a $F_{2}$ en l'avaluació de l'RCF és estat utilitzat en casos similars per simplificar la interpretació dels resultats.

3.2.3 Altres factors tenguts en compte en l'avaluació del risc de confusió fonològica

Els nivells d'RCF proposats a la secció precedent òbviament s'han de considerar com a categories arbitràries, modificables segons les necessitats metodològiques del recercador. A tal propòsit, és possible que les diferències acústiques incloses més damunt en la categoria d'RCF baix puguin, en alguns casos, ésser considerades com a portadores d'un risc en realitat $n u l$, i sobretot les que presenten diferències quantificables en pocs decimals de Barks. De fet, en literatura són disponibles diversos estudis que quantifi-

20. Per una altra banda, no se pot excloure que aquestes darreres realitzacions puguin ésser confoses $\mathrm{amb} / \mathrm{j}$, w/ per part de parlants d'altres varietats del català, però l'avaluació d'aquest risc aniria més enllà de l'abast del present treball — que mira a comparar exclusivament fonemes vocàlics — i mereixeria, creiem, un estudi específic en altra seu.

2I. Amb l'excepció de la comparació amb el mallorquí, vist que en aquest cas és possible suposar un risc de confusió amb /ə/. 
carien el difference limens (DL), ${ }^{22}$ o marge perceptiu mínim d'Fi per discriminar dos sons vocàlics, en Io/I5 Hz o 0,09-0,I3 Bark ${ }^{23}$ (Hawks 1994; Kewley-Port 1990), amb altres autors (Flanagan 1955; Mermelstain 1978; Labov 1994) que consideren aquest valor com a més elevat. ${ }^{24}$ Aplicant la proposta de Flanagan (I955) de considerar el DL en $26 \mathrm{~Hz}$ per a FI (circa O,22 Bark, calculat per una vocal amb FI $=500 \mathrm{~Hz}$ ), ${ }^{25}$ i de $60 \mathrm{~Hz}$ per a F2 (circa o,26 Bark, calculat per a una F2 de $1500 \mathrm{~Hz}$ ), el lector podrà considerar l'RCF baix com anàleg al risc nul quan la diferència acústica total entre dues vocals d'una varietat2 no supera els o,80/o,9o Bark per FI i I,oo Bark per F2.

Un altre factor que s'ha considerat en l'avaluació de l'RCF és estat la disposició tipològica de les vocals en un determinat sistema dialectal. Per exemple, relativament al gironí, aquest risc és estat calculat respecte a les vocals anteriors $\mathrm{i} / \mathrm{a} /$, que presenten una distribució en l'espai vocàlic similar a la d'altres varietats catalanes (Recasens $\&$ Espinosa 2009), alguerès inclòs. Pel que fa a la sèrie posterior, és prou sabut que el gironí presenta una fusió de $/ 0 / \mathrm{i} / \mathrm{o} /$ originals en $/ \mathrm{O} /{ }^{26} \mathrm{i}$ el nostre interès en aquest cas és estat avaluar si aquest fonema és acústicament més semblant a la vocal mitjana-baixa posterior $(/ \mathrm{J} /)$ de l'alguerès o a la corresponent vocal mitjana alta $(/ \mathrm{o} /)$. En manera anàloga, s'han comparat acústicament les vocals mitjanes alguereses amb $/ \mathrm{E} / \mathrm{i} / \mathrm{O} /{ }^{27}$ del rossellonès, per establir si els darrers s'assemblen acústicament més a les vocals mitjanes altes o mitjanes baixes de la primera varietat. Per motius d'asimetria en la disposició vocàlica dels dos sistemes (alguerès i rossellonès), en la comparació no s'ha calculat ningun RCF.

22. Mermelstain (1978) defineix el concepte de difference limens com «l'habilitat del sistema auditiu de diferenciar estímuls complexos amb un model espectral estacionari» («the ability of the whole auditory system to differentiate complex stimuli with stationary spectral patterns»).

23. Aquest valor és referible a dos sons vocàlics amb Fi proper a $500 \mathrm{~Hz}$.

24. Per exemple, Labov (1994: 360-364) indica en FI $=50 \mathrm{~Hz}$ el valor a dins del qual dues vocals properes de l'anglès americà deixen d'ésser contrastives.

25. Aquest mateix valor és estat proposat de Boersma (1998: I04) com a llindar del just noticeable difference (diferència a penes perceptible) entre dos sons propers.

26. Segons els resultats de Recasens \& Espinosa (2009), /0/ i /o/ són encara distingibles en termes de producció, tot i que no més en termes de percepció.

27. Per a una descripció general del sistema vocàlic tònic del rossellonès, veg. Recasens (I996, especialment cap. II). 


\section{RESULTATS I DISCUSSIÓ}

La taula 3 inclou els valors en Bark dels primers dos formants ( $\mathrm{F}_{1}$ i F2) de les vocals tòniques de les 7 varietats considerades, i també els valors originals en $\mathrm{Hz}$ presentats en Ballone (2013) i Recasens \& Espinosa (2006 i 2009). A seguir, la taula 4 presenta un resum dels resultats de l'avaluació del risc de confusió fonològica per cada vocal considerada.

\begin{tabular}{|c|c|c|c|c|c|c|c|c|c|c|c|c|c|c|c|}
\hline \multicolumn{4}{|l|}{ alg. } & \multicolumn{4}{|c|}{ n-occ. } & \multicolumn{4}{|l|}{ val. } & \multicolumn{4}{|c|}{ centr. } \\
\hline FI & $\mathrm{F}_{2}$ & FI (B) & $\mathrm{F}_{2}(\mathrm{~B})$ & $\mathrm{F}_{\mathrm{I}}$ & $\mathrm{F}_{2}$ & $\overline{F I}(\mathrm{~B})$ & $\mathrm{F}_{2}(\mathrm{~B})$ & $F_{I}$ & $\mathrm{~F}_{2}$ & FI (B) & $\mathrm{F}_{2}(\mathrm{~B})$ & $\mathrm{F}_{\mathrm{I}}$ & $\mathrm{F}_{2}$ & $\overline{F I}(B)$ & $\mathrm{F}_{2}(\mathrm{~B})$ \\
\hline 348 & 2145 & $3,5 \mathrm{I}$ & 13,47 & 323 & 2128 & 3,26 & $\mathrm{I} 3,4 \mathrm{I}$ & 322 & 2145 & 3,25 & $\mathrm{I} 3,47$ & 334 & 2078 & 3,37 & 13,25 \\
\hline 437 & 2014 & 4,36 & 13,05 & $44^{8}$ & I854 & 4,46 & I2,49 & 460 & I837 & 4,56 & $\mathrm{I} 2,43$ & 450 & I839 & 4,47 & $\mathrm{I} 2,44$ \\
\hline 556 & I798 & 5,39 & 12,29 & 595 & 1665 & $5,7 \mathrm{I}$ & II, 78 & 6oI & 1764 & 5,75 & $\mathrm{I} 2, \mathrm{I} 6$ & 58I & 1700 & 5,59 & II, 92 \\
\hline 737 & I354 & 6,79 & IO,4I & 676 & I4IIS & 6,34 & 10,70 & $68 \mathrm{I}$ & I4I 19 & 6,3 & 10,72 & 730 & 1358 & 6,74 & Io,44 \\
\hline 539 & IOI9 & 5,25 & 8,64 & 586 & II 42 & 5,64 & 9,34 & 621 & II 58 & 5,92 & 9,42 & 608 & 1125 & 5,82 & 9,25 \\
\hline 446 & 962 & 4,44 & 8,29 & 477 & 1065 & 4,72 & 8,90 & 493 & 1059 & 4,86 & 8,86 & 489 & IO47 & 4,82 & 8,80 \\
\hline 360 & 936 & 3,63 & 8,13 & 372 & 942 & 3,74 & 8,16 & 370 & 923 & 3,72 & 8,05 & 394 & 960 & 3,96 & 8,28 \\
\hline
\end{tabular}

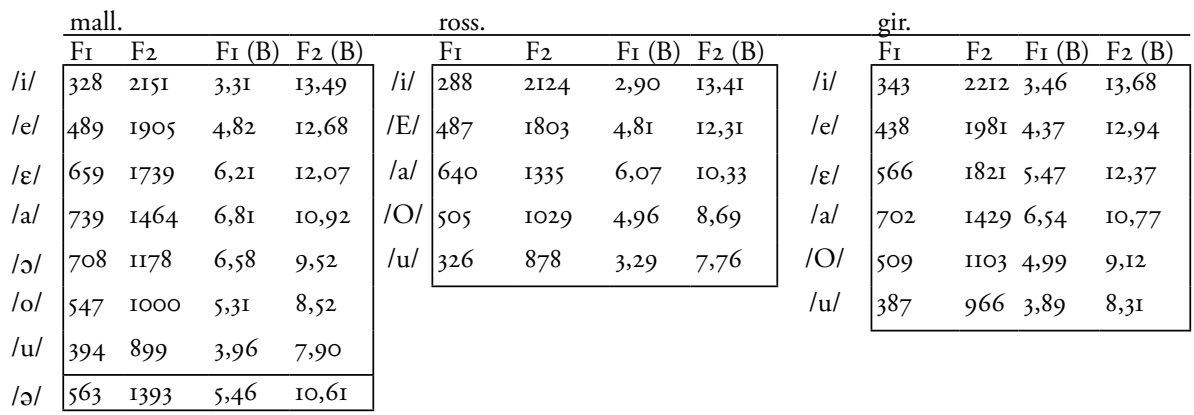

Taula 3. Valors $\mathrm{F}_{\mathrm{I}}$ i $\mathrm{F}_{2}$ en $\mathrm{Hz}$ in en Bark (B) de les vocals tòniques de 7 varietats catalanes. Els valors $\mathrm{de} / \mathrm{E} / \mathrm{i} / \mathrm{O} /$ en rossellonès s'han calculat amitjanant els valors de /E/ i /e/, i de $\mathrm{o} / \mathrm{i} / \mathrm{o} /$ en Recasens \& Espinosa (2009, taula 3). Igualment, s'ha calculat aquí el valor de /O/ del gironí amitjanant els valors de /o/ i /o/ a la mateixa taula. 


\begin{tabular}{|c|c|c|c|c|c|c|c|c|c|c|c|}
\hline & & \multicolumn{2}{|c|}{ n-occ. } & \multicolumn{2}{|c|}{ val. } & \multicolumn{2}{|c|}{ centr. } & \multicolumn{2}{|c|}{ mall. } & \multicolumn{2}{|c|}{ gir. } \\
\hline \multirow{7}{*}{ 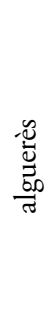 } & $/ \mathrm{i} /$ & $1 ; 0$ & $(/ \mathrm{e} /)$ & $1 ; 0$ & $(/ \mathrm{e} /)$ & $1 ; 0$ & $(/ \mathrm{e} /)$ & $1 ; 0$ & $(/ \mathrm{e} /)$ & $1 ; 2$ & $(/ \mathrm{e} /)$ \\
\hline & le/ & $1 ; 3$ & $(/ \mathrm{i} /)$ & $1 ; 3$ & $(/ \mathrm{i} /)$ & $1 ; 3$ & $(/ \mathrm{i} /)$ & $2 ; 2$ & $(/ \mathrm{i} /)$ & $1 ; 1$ & $(/ \mathrm{i} /)$ \\
\hline & $|\varepsilon|$ & $1 ; 3$ & $(/ \mathrm{e} /)$ & $2 ; 2$ & $(/ \mathrm{e} /)$ & $1 ; 3$ & $(/ \mathrm{e} /)$ & $3 ; 2$ & $(/ \mathrm{e} /)$ & $1 ; 0$ & $(/ \mathrm{e} /)$ \\
\hline & $\mid \mathrm{a} /$ & 0 & & 0 & & 0 & & $1 ; 2$ & $(/ \mathrm{\jmath} /)$ & 0 & \\
\hline & $10 /$ & $2 ; 4$ & $(/ \mathrm{o} /)$ & $3 ; 4$ & $(/ \mathrm{o} /)$ & $3 ; 4$ & $(/ \mathrm{o} /)$ & $4 ; 4$ & $(/ \mathrm{o} /)$ & (n.c.) & \\
\hline & $/ \mathrm{o} /$ & $2 ; 4$ & $(/ \mathrm{u} /)$ & $2 ; 4$ & $(/ \mathrm{u} /)$ & $2 ; 4$ & $(/ \mathrm{u} /)$ & $3 ; 2$ & $(/ \mathrm{u} /)$ & (n.c.) & \\
\hline & $/ \mathrm{u} /$ & 0 & & 0 & & 0 & & 0 & & (n.c.) & \\
\hline
\end{tabular}

RCF nul (0), baix (1), mitjà (2), alt (3), molt alt (4)

Taula 4. Resum del risc de confusió fonològica (RCF) per les varietats considerades, amb l'excepció del rossellonès. ${ }^{28}$ En cada columna és indicat el nivell de risc combinat $\mathrm{FI}_{\mathrm{F}} \mathrm{F}_{2}{ }^{29}$ respecte a cada u dels 7 fonemes vocàlics algueresos. Entre parèntesis és indicat el fonema respecte al qual s'ha calculat l'RCF ${ }^{30}$ Quan un RCF no és estat calculat per motius lligats a les diferències fonològiques entre les varietats (veg. més damunt $\$ 3.2 .3$ ) la cel.la presenta la sigla «(n.c.)» (no calculat).

Abans de comentar els resultats, pot ésser útil presentar les comparacions gràfiques entre la col-locació acústica (en Bark ${ }^{31}$ ) de les vocals alguereses i les corresponents en les altres varietats catalanes. Aquesta comparació, presentada a la figura 3, té com a objectiu permetre una interpretació més immediata i intuïtiva de les dades.

28. Recordem que la taula té com a objectiu fornir una mostra general de l'RCF calculat en el present treball, mentre que la comparació acústica entre les vocals de l'alguerès i les del rossellonès té com a objectiu principal establir si els fonemes /E/ i /O/ de la darrera varietat s'assemblen acústicament més a les vocals mitjanes tancades o a les vocals mitjanes obertes de l'alguerès.

29. La diversa grandària del caràcter utilitzat vol recordar el pes diferent atribuït en aquest estudi a $F_{I}$ i F2 en termes acusticoperceptius.

30. Les dades presentades a la taula s'han de llegir en la manera següent: (primeres dues cel-les a dalt, a mà esquerra) «la /i/ algueresa té un risc baix, en termes d'FI, i nul, en termes d'F2, d'ésser confosa amb /e/ per part d'un parlant del català nord-occidental».

3I. Les corresponents comparacions en $\mathrm{Hz}$ seran presentades gràficament a l'apèndix I. 
FranCESC BALlone

Sobre la correcta interpretació dels fonemes vocàlics de l'alguerès: un estudi acústic
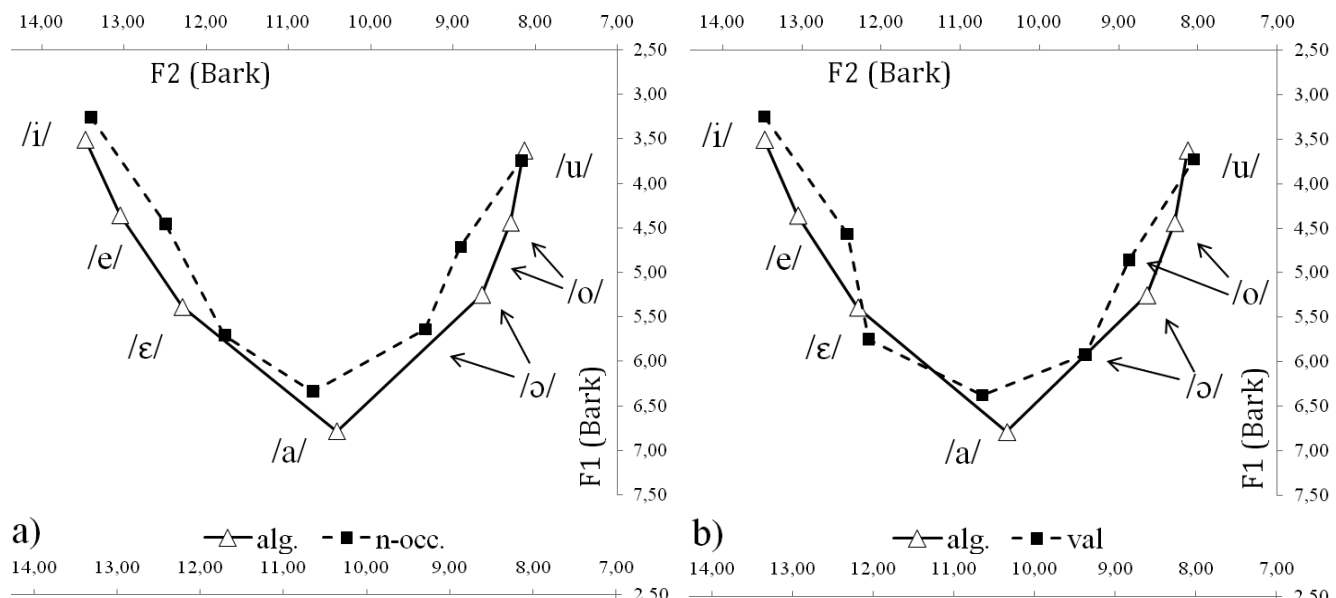

b) $\quad-$ alg. - - - val
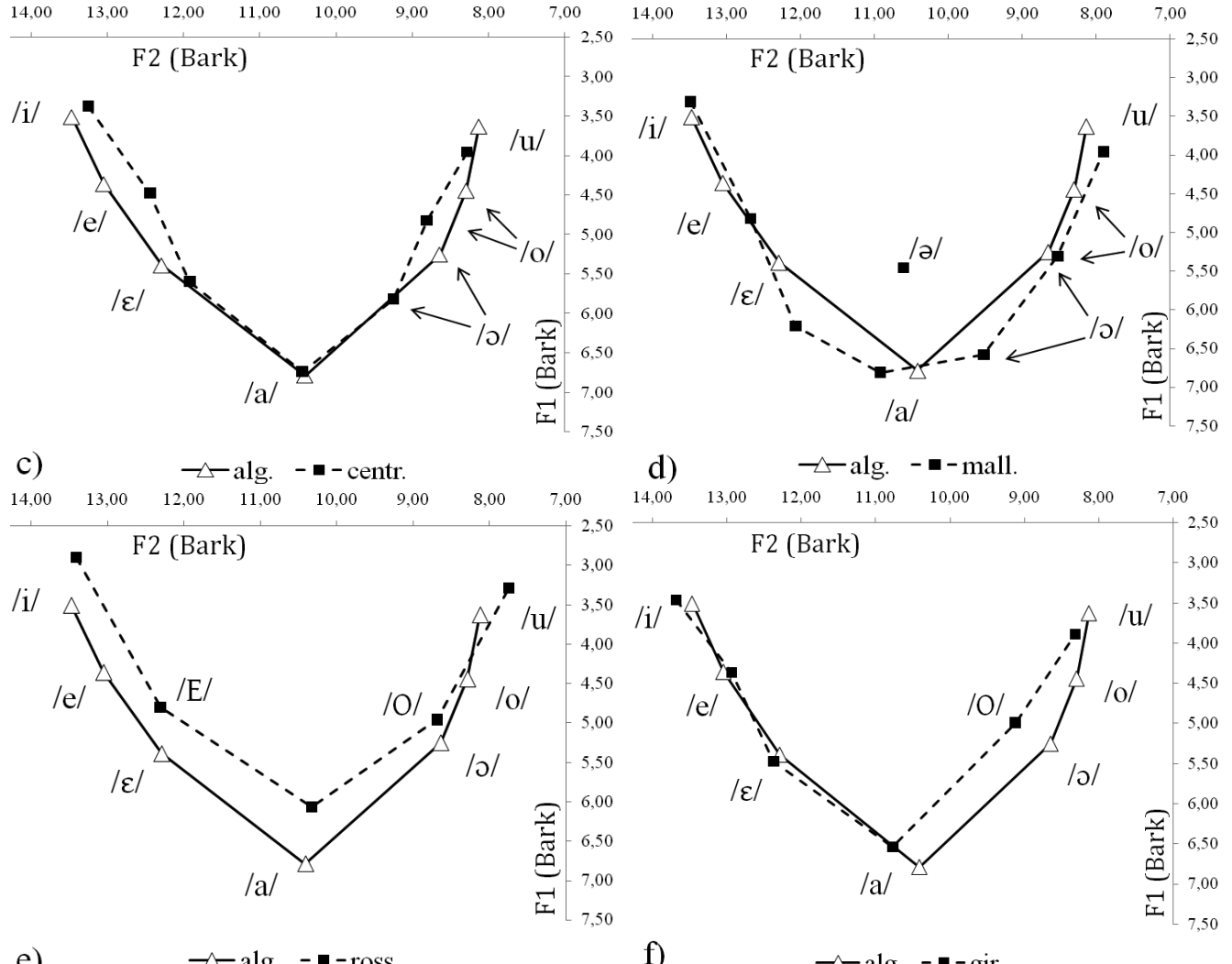

e)

$\neg$ alg. - - - ross.

f)

- alg. - - gir.

Figura 3. Comparació dels valors FI i F2 (Bark) dels fonemes vocàlics de l'alguerès amb els corresponents en sis varietats del català. 
Una primera consideració bastant evident és que l'alguerès posseeix vocals mitjanes perceptibles com a més tancades respecte a les corresponents en les altres varietats, coherentment amb els valors presentats a la fig. I i a les consideracions en (Ib) i (Ic). Per una altra banda, els resultats contradiuen (Ia) en el sentit que /e/ de l'alguerès no resulta "especialment centralitzada i posterior», vist que aquesta vocal és, al contrari, perceptible com a més alta i més anterior respecte a les altres varietats, amb l'excepció del gironí, que presenta una /e/ acústicament molt semblant a la de l'alguerès. Relativament a les vocals tancades $/ \mathrm{i}, \mathrm{u} /$, les diferències acústiques entre alguerès i les altres varietats són menys evidents, amb l'excepció del rossellonès, on aquesta sèrie és clarament perceptible com a més alta respecte a la sèrie corresponent en alguerès. Pel que fa a /a/, aquest fonema és perceptible com a més obert en alguerès respecte al corresponent en nord-occidental, valencià, rossellonès i gironí, i tan obert com el del català central i mallorquí.

Aquí baix seran discutits els nivells de risc de confusió fonològica resumits més damunt a la taula 4, en funció de 3 grups vocàlics amb un nivell d'RCF creixent: vocals perifèriques $(/ \mathrm{i}, \mathrm{a}, \mathrm{u} /)$, mitjanes anteriors $(/ \mathrm{e}, \varepsilon /)$, mitjanes posteriors $(/ \mathrm{o}, \mathrm{o} /)$ :

(a) vocals periferiques $(/ \mathrm{i}, \mathrm{a}, \mathrm{u} /)$. Aquest grup de vocals alguereses és el que presenta nivells més baixos d'RCF, amb una valor $n u l$ per /u/ i /a/ respecte a totes les varietats; l'única excepció en aquest sentit és relativa al mallorquí, pel qual la /a/ algueresa presenta un risc baix $\mathrm{F}^{32}$ i mitjà $\mathrm{F}_{2}$ d'ésser confosa amb/o/. Relativament a /i/, aquesta vocal és més baixa en alguerès que en les altres varietats, i presenta un risc (tot plegat) baix d'ésser confosa amb /e/ en termes d'FI, i un risc nul en termes d'F2, amb l'excepció del gironí, que presenta un RCF d'F2 mitjà. Per resumir, les vocals perifèriques de l'alguerès presenten quasi sempre un risc nul o baix d'ésser confoses amb altres vocals, amb un parells de casos de risc mitjà en termes d'F2;

(b) vocals mitjanes anteriors $(/ \mathrm{e}, \varepsilon /)$. Aquestes vocals són més altes en alguerès respecte a les corresponents en altres varietats, amb diferències d'Fi evidents respecte al mallorquí (risc alt de confondre /E/ amb /e/ i mitjà de confondre /e/ amb/i/) i al valencià pel que fa a $/ \varepsilon /$ (risc mitjà de confondre aquesta vocal amb/e/). En tots els altres asos, l'RCF d'Fi és baix. Relativament a $\mathrm{F}$ 2, l'RCF és pràcticament inexistent respecte al gironí (baix per /e/ i $n u l$ per / $/$ /), mentre que en els altres casos l'RCF oscil.la entre mitjà (/e, $\varepsilon /$ mallorquí i /e/ valencià) i alt (tots els altres casos). En altres paraules, un parlant gironí té molt poques probabilitats de confondre les /e/ i / $/ \varepsilon /$ alguereses amb /i/ i /e/, respectivament (RCF baix/baix i baix/nul), mentre que aquest

32. A partir d'ara i fins a la fi del present treball, FI i F2 s'han de llegir com a Fi Bark i F2 Bark. 
risc és molt més concret per un parlant mallorquí (RCF mitjàlmitjà i alt/mitjà) i per un parlant valencià relativament a $/ \varepsilon /(\mathrm{RCF}$ mitjàlmitjà). En tots els altres casos, si hi ha alguna possibilitat de confondre /e/ i / $/$ / alguereses $\mathrm{amb} / \mathrm{i} / \mathrm{i} / \mathrm{e} /$, això seria degut més a diferències en termes d'F2 (RCF alt) que no en termes d'FI (RCF baix). Aquest aspecte queda clar si se torna a mirar la figura 3, que mostra com les vocals mitjanes anteriors de l'alguerès siguin en general (amb la sòlita excepció del gironí) més avançades respecte a les vocals corresponents de les altres varietats;

(c) vocals mitjanes posteriors $(/ \mathrm{o}, \mathrm{o} /)$. Aquesta és la sèrie que presenta l'RCF més elevat. En termes d'F2, la vocal / $/$ / de l'alguerès presenta un risc molt alt d'ésser confosa amb /o/ en totes les varietats considerades, ${ }^{33} \mathrm{i}$ la vocal corresponent mitjana alta /o/ presenta un risc anàleg d'ésser confosa $\mathrm{amb} / \mathrm{u} /$ en nord-occidental, valencià i central, risc que, però, baixa a mitjà pel que fa al mallorquí. Relativament a Fi, el risc de confondre $/ \mathrm{o} / \mathrm{amb} / \mathrm{u} /$ oscil-la entre mitjà (nord-occidental, valencià i central) i alt (mallorquí), mentre que el risc de confondre / / a a /o/ augmenta amb la progressió nord-occidental, valencià/central, mallorquí (mitjà, alt i molt alt, respectivament).

La figura 4 resumeix l'RCF combinat $\mathrm{FIx} \mathrm{F}_{2}{ }^{34}$ en funció de vocal i dialecte.

33. Recordem que, a causa de la fusió en gironí de /o/ i / / en /O/, les vocals posteriors d'aquesta varietat són estades excloses del càlcul d'RCF.

34. La base de dades del gràfic és constituïda pels valors numèrics presentats a la taula 4. El valor combinat FIx F2 s'ha calculat en la manera següent: al valor RCF o-4 de l'FI de cada vocal de cada dialecte s'ha sumat el valor corresponent $\mathrm{F}_{2}$ dividit per 2, per tal d'obtenir un resultat on la component acústicament més important (és a dir, FI) jugui un paper més important respecte a F2. Per exemple, el valor numèric combinat de /e/ alguerès respecte al n-occ. mostrat a la figura 4 és I;3: els dos nombres s'han sumat de la manera següent: $\mathrm{I}+(3 / 2)=2,5$. 
RCF combinat F1xF2 per vocal i dialecte

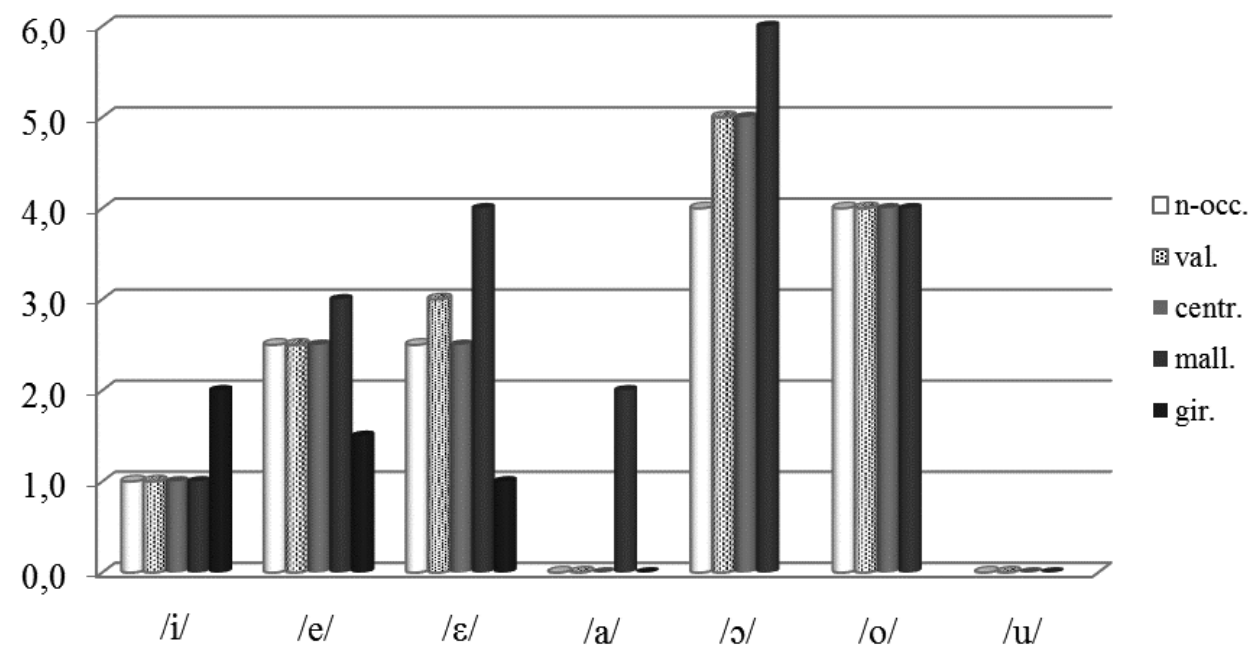

Figura 4. Risc de confusió fonològica en funció de vocal i dialecte, amb l'exclusió del rossellonès i de les vocals posteriors del gironí.

La figura mostra en manera clara algunes tendències descrites al llarg de la present secció, és a dir: l'RCF és més elevat en les vocals mitjanes respecte a les vocals perifèriques $i$, en la primera categoria, és més elevat en les vocals posteriors, i especialment / $/$. Del punt de vista de les varietats individuals, en diversos casos (/e, $\varepsilon, a, \Im /)$ el dialecte que presenta un RCF combinat més elevat és el mallorquí.

Com s'ha anticipat al final de $\$ 3.2 .3$, no s'ha calculat cap RCF entre alguerès i rossellonès, i s'ha dedicat al contrari atenció a avaluar quines vocals mitjanes de la primera varietat presenten les distàncies acústiques més reduïdes respecte a /E/ i /O/ del rossellonès. En termes d'FI, ambdós fonemes serien més semblants a $/ \varepsilon / \mathrm{i} / \mathrm{\jmath} / \mathrm{de}$ l'alguerès, tot i que és possible que aquesta major proximitat no resulti clara del punt de vista perceptiu. ${ }^{35}$ La mateixa proximitat seria al contrari més evident en termes d'F2, vist que aquest formant és quasi idèntic per $/ E / \mathrm{i} / \varepsilon /$, i per $/ \mathrm{O} / \mathrm{i} / \mathrm{\rho} /$ de les dues varietats. Per això, considerant conjuntament els valors d'Fi i F2, és més probable que

35. De fet, havem calculat en o,I4 Bark la major proximitat de / $/$ / respecte a / $/$ / vs. /e/ de l'alguerès; aquesta diferència no seria perceptible segons el difference limen proposat per Flanagan (1955) (0,22 Bark). Per altra banda, no se pot excloure que sigui possible percebre la major proximitat acústica de /O/ amb /o/ vs. /o/ de l'alguerès, vist que la diferència (o,22 Bark) correspon al llindar mínim de percepció proposat per Flanagan. 
un parlant rossellonès pugui classificar d'una manera impressionista les vocals mitjanes pròpies com a més semblants a les vocals mitjanes obertes que no a les mitjanes tancades de l'alguerès. Recordem que una comparació acústica similar és estada feta també entre /o/ i / / / alguereses i /O/ del gironí. Com a resultat, la darrera vocal tendria més possibilitats d'ésser associada a la / / / de l'alguerès, sobretot en termes d'F2. ${ }^{36}$

Els resultats presentats en aquesta secció suporten la hipòtesi de base del present estudi, segons la qual alguns errors freqüents en la interpretació de les vocals (sobretot mitjanes) alguereses poden tenir també causes de tipus acusticoperceptiu. En general, les vocals alguereses mitjanes posteriors són pronunciades més altes i més posteriors, $\mathrm{i}$ les mitjanes anteriors són pronunciades més altes (tot i que amb diferències acústiques menors respecte a la sèrie posterior) i anteriors respecte a les vocals corresponents en altres varietats catalanes.

Si això és estat comprovat en termes de comparació de dades dialectals amitjanades a través de parlants, no s'ha tampoc exclòs la possibilitat que variables com la variabilitat acústica per parlant puguin també, en alguns casos, afectar el nivell d'RCF. A tal propòsit, la figura 5 presenta els resultats d'una primera comparació exploratòria entre les vocals del català central i les vocals corresponents produïdes per cada u del cinc informants algueresos entrevistats. ${ }^{37}$

36. Relativament a aquesta dimensió, la /O/ gironina és o,35 Bark més propera a / / respecte a /o/ de l'alguerès. També en termes d'Fi la diferència és favorable a / $/$ / algueresa, però de o,I4 Bark només.

37. Els mateixos valors relatius als parlants algueresos són presentats en forma numèrica (Barks i $\mathrm{Hz})$ a l'apèndix II. 
Francesc Ballone

Sobre la correcta interpretació dels fonemes vocàlics de l'alguerès: un estudi acústic

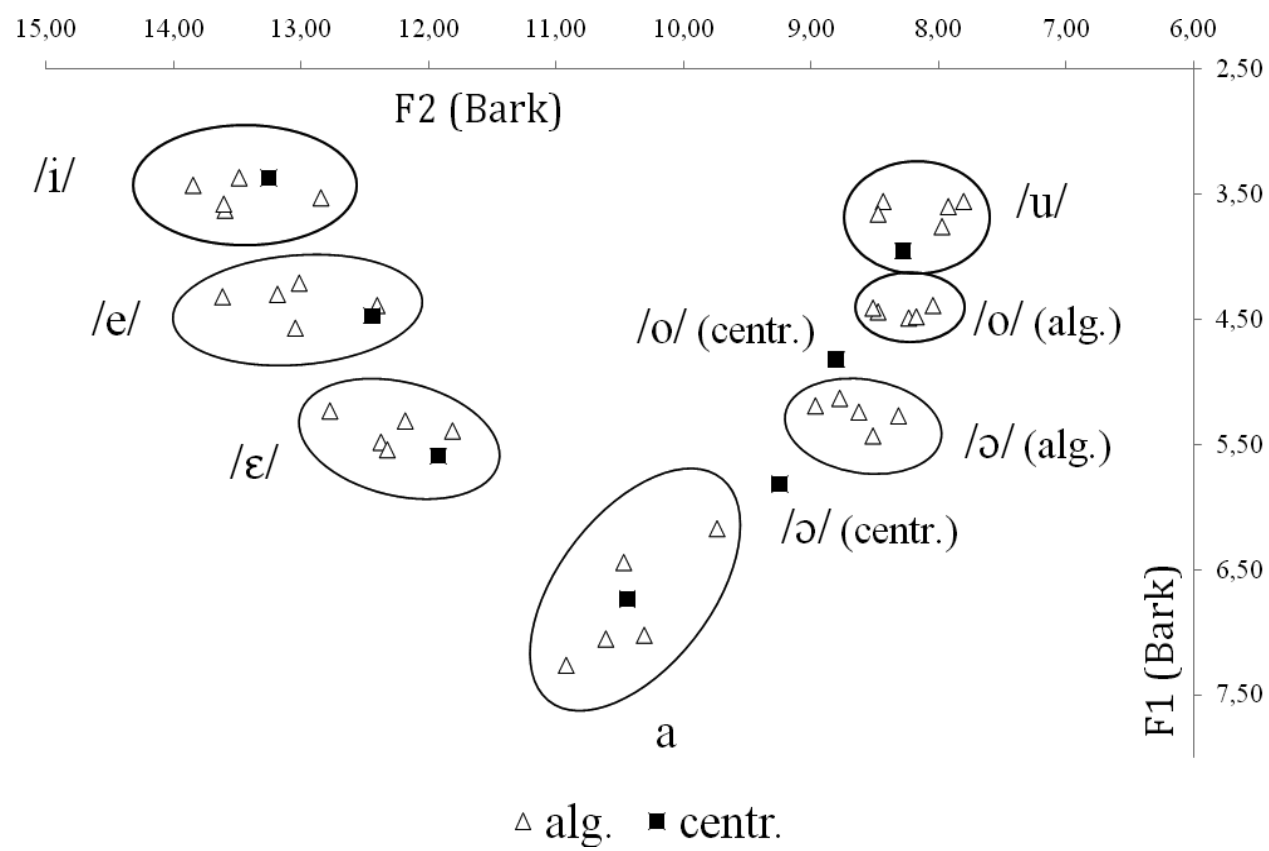

Figura 5. Comparació entre els valors formàntics (en Bark) de les vocals tòniques del català central i de les vocals corresponents produïdes individualment per cinc parlants natius d'alguerès.

Segons les dades de la figura, la possibilitat d'identificar correctament la tipologia d'una vocal algueresa pot dependre, en part, també de la variabilitat en funció del parlant. Un cas molt interessant és el de la distribució en l'espai vocàlic de les cinc realitzacions alguereses de /a/. En quatre d'aquestes, l'RCF és definible nul, mentre

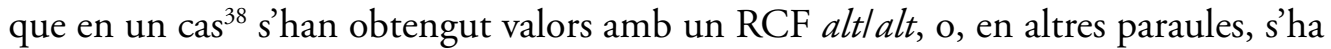
trobat un locutor alguerès que produeix valors mitjans de / $\mathrm{a} /$ facilment confusibles $\mathrm{amb} / \mathrm{\rho} /$ per part d'un parlant central. Igualment, si mirem les realitzacions alguereses $\mathrm{de} / \varepsilon /$, aquestes presenten tendencialment un risc $\mathrm{F} 2$ alt d'ésser interpretades com a /e/, tret d'un cas, on el mateix risc se pot considerar $n u l$. Conclusions similars, sobretot en termes de diferències $\mathrm{d}^{\prime} \mathrm{F} 2$, són també aplicables a /e/, / / /, i /o/.

Les consideracions fetes en la present secció no exclouen que també altres factors puguin influir sobre la correcta interpretació dels fonemes vocàlics algueresos. Per exemple, en alguerès el timbre de les vocals mitjanes baixes (i sobretot $/ \mathrm{o} /$ ) és alterat

38. Veg. informant SM a la taula de l'apèndix II. 
FranCESC BALLONE

Sobre la correcta interpretació dels fonemes vocàlics de l'alguerès: un estudi acústic

ocasionalment per la pressió de la metafonia sarda. ${ }^{39}$ En aquest sentit, no és impossible sentir avui en dia pronúncies — que poden canviar en funció del locutor- com [as'toria] i [pa'rokia] (història, parròquia) en lloc dels esperats [as'toria] i [pa'rokia]. Per totes aquestes raons, creiem que individuar correctament les vocals alguereses, del punt de vista fonològic, pot representar una tasca no sempre facil fins i tot per lingüistes que coneixen bé aquesta varietat.

\section{CONCLUSIONS}

Segons les dades analitzades en el present treball, /e/ i / $\varepsilon /$ de l'alguerès són normalment més altes i anteriors respecte a les vocals corresponents en les altres varietats catalanes considerades, i / / i /o/ més altes i posteriors. Aquests resultats confirmen algunes descripcions presents en bibliografia, segons les quals l'alguerès fa part de les varietats catalanes que posseeixen variants diatòpiques de $/ \varepsilon / \mathrm{i} / \supset /$ més tancades (Recasens 1996), i contradiuen la hipòtesi que la /e/ algueresa sigui «especialment centralitzada i posterior» (Recasens 1996; Kuen 1932). En relació a l'objectiu principal del present treball, és a dir comprendre si la interpretació freqüent en literatura de /E/ i / / alguereses com a /e/ i /o/ pot tenir una causa de tipus acústic, la resposta és segurament positiva. En termes dialectals, les distàncies acústiques majors relativament a les vocals mitjanes s'han trobat entre alguerès i mallorquí, mentre que les distàncies acústiques menors s'han trobat entre la primera varietat i el gironí pel que fa a la sèrie anterior. Si considerem les dades obtengudes en funció de la variable vocal, el risc combinat Fix $F_{2}$ de confusió fonològica és més elevat en la sèrie mitjana posterior, $\mathrm{i}$ sobretot $/ \mathrm{\rho} /$, seguit per la sèrie mitjana anterior, que encara presenta riscs de confusió no irrellevants, sobretot en termes d'F2. Un RCF normalment nul o baix és al contrari atribuïble a les vocals perifèriques. Pel que fa a les vocals /E/ i /O/ del rossellonès, i $/ \mathrm{O} /$ del gironí, aquestes presenten característiques formàntiques $\mathrm{F}_{\mathrm{x}} \mathrm{F}_{2}$ més similars $\mathrm{a} / \varepsilon / \mathrm{i} / \mathrm{o} /$ que no a /e/ i /o/ de l'alguerès.

En l'estudi havem citat també altres variables que podrien en teoria condicionar el risc de confusió fonològica. Una és la variabilitat en funció del parlant, analitzada amb dades exploratòries a la Figura 5. De fet, la figura indica (entre d'altres) el cas

39. Per a una descripció general de la metafonia sarda, veg. Spano (I840: 5), Wagner (194I/1984: 3I), Contini (1987: 439, 442); sobre els límits d'aquestes descripcions tradicionals, veg. Ballone (2013, $\$ 6.4)$. En la sua formulació més senzilla, la metafonia sarda pot ésser descrita com el procés pel qual les vocals mitjanes d'aquesta llengua presenten un timbre tancat si són directament seguides per una vocal alta o mitjana alta, i un timbre obert si són seguides per una vocal baixa o mitjana baixa. 
d'un locutor alguerès que produeix una / $\mathrm{a} /$ particularment alta i posterior, la qual presenta un risc combinat $\left(\mathrm{F}_{\mathrm{Ix}} \mathrm{F}_{2}\right)$ alt d'ésser confosa amb /o/ per part d'un locutor català central..$^{40}$ Una altra variable que pot en teoria crear problemes per interpretar correctament les vocals mitjanes del català de l'Alguer és la pressió de la metafonia sarda, un fenomen harmònic encara poc conegut en termes estadístics en alguerès, ${ }^{41}$ i que mereixeria d'ésser aprofundit en recerques futures.

Francesc Ballone

Universitat Autònoma de Barcelona

francesco.ballone@libero.it

\section{REFERÈNCIES BIBLIOGRÀFIQUES}

Ballone, F. (2008) «Català de l'Alguer. Distribució i anàlisi experimental dels fonemes vocàlics», tesina de llicenciatura, Università degli Studi di Sassari, Facoltà di Lingue e Letterature Straniere.

- (2010) "Characterisation of Sardinian metaphony in the Italian of Alghero and possible effects on Algherese Catalan», tesina de llicenciatura (curs magistral), Università degli Studi di Sassari, Facoltà di Lingue e Letterature Straniere.

- (2013) «An acoustic study of Sardinian and Algherese Catalan Vowels», tesi doctoral, Universitat Autònoma de Barcelona.

Boersma, P. (1998) Functional Phonology, The Hague, Holland Academic Graphics.

Contini, M. (1987) Étude de géographie phonétique et de phonétique instrumentale du sarde, Alessandria, Dell'orso.

Corbera, J. (2000) Caracterització del lèxic alguerès, Calvià, Universitat de les Illes Balears.

Coromines, J. (1936) «El parlar de Cardós i Vall Ferrera», Butlletí de Dialectologia Catalana, 23, pp. 24I-33I.

Flanagan, J. L. (1955) «A difference limen for vowel formant frequency», Journal of the Acoustical Society of America, 27, pp. 613-617.

Guarnerio, P. E. (I886) «Il dialetto catalano di Alghero», dins Archivio Glottologico Italiano, Roma/Torí/Florència, Loescher.

40. Un risc de confusió anàleg per les mateixes vocals és detectable també en la comparació alguerèsvalencià $\mathrm{i}$ alguerès-mallorquí, tal com pot ésser comprovat a partir dels valors presentats a l'Apèndix II.

4I. Per conèixer les avaluacions sobre aquest fenomen en un nombre molt limitat de casos, veg. Ballone 20 oro.

Caplletra 60 (Primavera, 2016), pp. 55-77 
FranCESC BALlone

Sobre la correcta interpretació dels fonemes vocàlics de l'alguerès: un estudi acústic

Hawks, J. W. (1994) «Difference limens for formant patterns of vowel sound», Journal of theAcoustical Society of America, 95, pp. 1074-1084.

Kewley-PoRT, D. (1990) «Thresholds for formant-frequency discrimination in isolated vowels", Journal of the Acoustical Society of America, suplement I 87, Sis9.

Kuen, H. (1932) «El dialecto de l'Alguer y su posición en la historia de la lengua catalana», Anuari de l'Oficina Romànica de Lingüistica i Literatura, vol. 5, Barcelona, Biblioteca Balmes, pp. I2I-I77.

- (1934) «El dialecto de l'Alguer y su posición en la historia de la lengua catalana», Anuari de l'Oficina Romànica de Lingüistica i Literatura, vol. 7, Barcelona, Biblioteca Balmes, pp. 4I-II2.

Labov, W. (1994) Principles of linguistic change: Internal factors, Oxford, Blackwell.

Lindblom, B. (1975) «Experiments in sound structure», Plenary address, 8th International Congress of Phonetic Sciences, Leeds, England.

— (1986) «Phonetic universals in vowel systems», dins J. J. Ohala i J. J. Jaeger (eds.), Experimental phonology, London, Academic Press, pp. 13-42.

Manunta, F. (1988) Cançons i líriques religioses de l'Alguer catalana, vol. I, l'Alguer, La Celere.

Mermelstein, P. (1978) «Difference limens for formant frequencies of steady-state and consonant-bound vowels", Journal of the Acoustical Society of America, 63 , pp. 572-580.

Morosi, G. (I886) «L'odierno dialetto catalano di Alghero in Sardegna», dins Miscellanea di filologia, dedicata alla memoria dei professori N. Caix e U. Canello. Florència, successori Le Monnier, pp. 312-332.

Navarro Tomás, T. \& M. Sanchis Guarner (1934) «Análisis fonético del valenciano literario", Revista de Filología Española, 2I, pp. II3-I4I.

Oppo, A., G. Lupinu, A. Mongili, R. Spiga, S. Perra \& M. Valdes (2007) Le lingue dei sardi. Una ricerca sociolinguistica. [Disponible en línia a <http://www. regione.sardegna.it/documenti/I_4_200705IOI34456.pdfs, consulta 03/03/2014.]

ReCasens, D. (1996) Fonètica descriptiva del català: assaig de caracterització de la pronúncia del vocalisme $i$ consonantisme del català al s. XX, Barcelona, Institut d'Estudis Catalans.

ReCASEns, D. \& A. Espinosa (2006) «Dispersion and variability of Catalan vowels», Speech Communication, 48, pp. 645-666.

- (2009) "Dispersion and variability in Catalan five and six peripheral vowel systems», Speech Communication, 5I, pp. 240-258.

Sanna, J. (1988) Diccionari català de l'Alguer, Alghero/Barcelona, Fundació del II Congrés de la Llengua Catalana. 
Serra, G. (1927) «Aggiunte e rettifiche algheresi all'"Atlas linguistic de Catalunya” di A. Griera» (cc. I/586)", L'Italia dialettale, vol. III, pp. 197-216.

Spano, G. (I995 [ra ed. I840]) Ortografia sarda, Cagliari, Gia Editrice.

TraunmÜller, H. (I990) «Analytical expressions for the tonotopic sensory scale», Journal of the Acoustical Society of America, 88, pp. 97-100.

VenY, J. (2002 [Ia ed. 1982]) Els parlars catalans. Sintesi de dialectologia, Palma de Mallorca, Moll.

Wagner, M.L. (1984 [ra ed. 194I]) Fonetica storica del sardo, edició a cura de G. Paulis, Cagliari, Trois.

- (1997 [Ia ed. 1950]) La lingua sarda. Storia, spirito e forma, Nuoro, Ilisso.

ZwICKER, E. (196I) «Subdivision of the audible frequency range into critical bands», Journal of the Acoustical Society of America, vol 33, núm. 2, p. 248.

\section{APÈNDIX I}

Comparació dels valors $F_{1}$ i F2 $(\mathrm{Hz})$ de les vocals tòniques de l'alguerès amb els valors corresponents en sis varietats del català (nord-occidental, valencià, central, mallorquí, gironí, rossellonès).
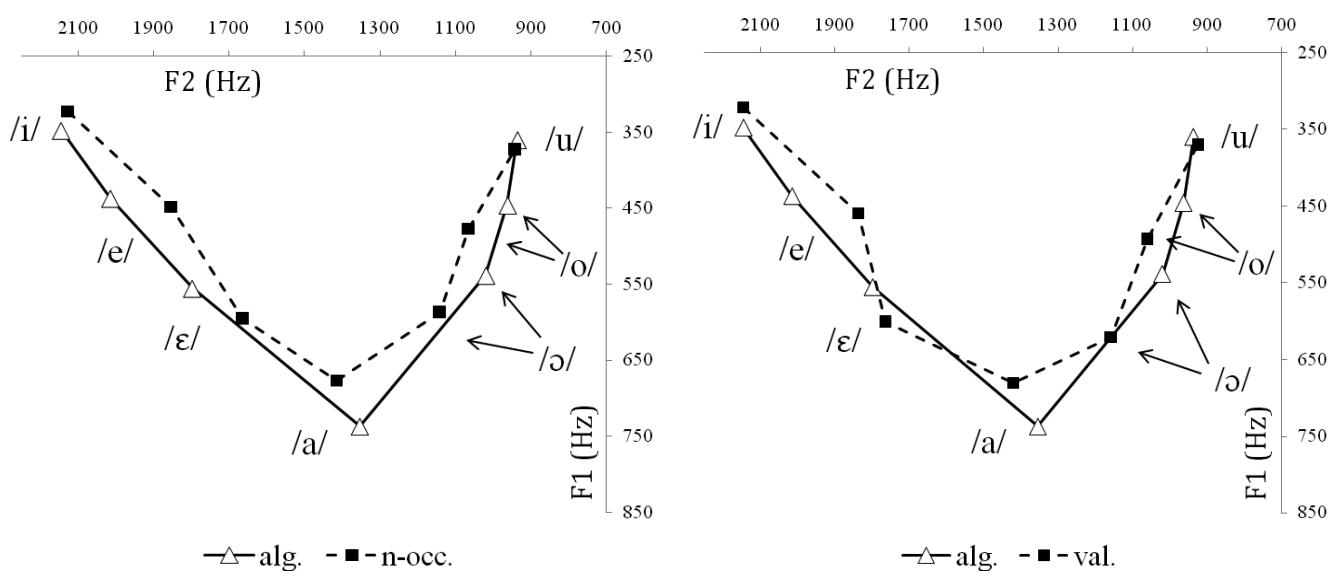
FranCESC BALLONE

Sobre la correcta interpretació dels fonemes vocàlics de l'alguerès: un estudi acústic
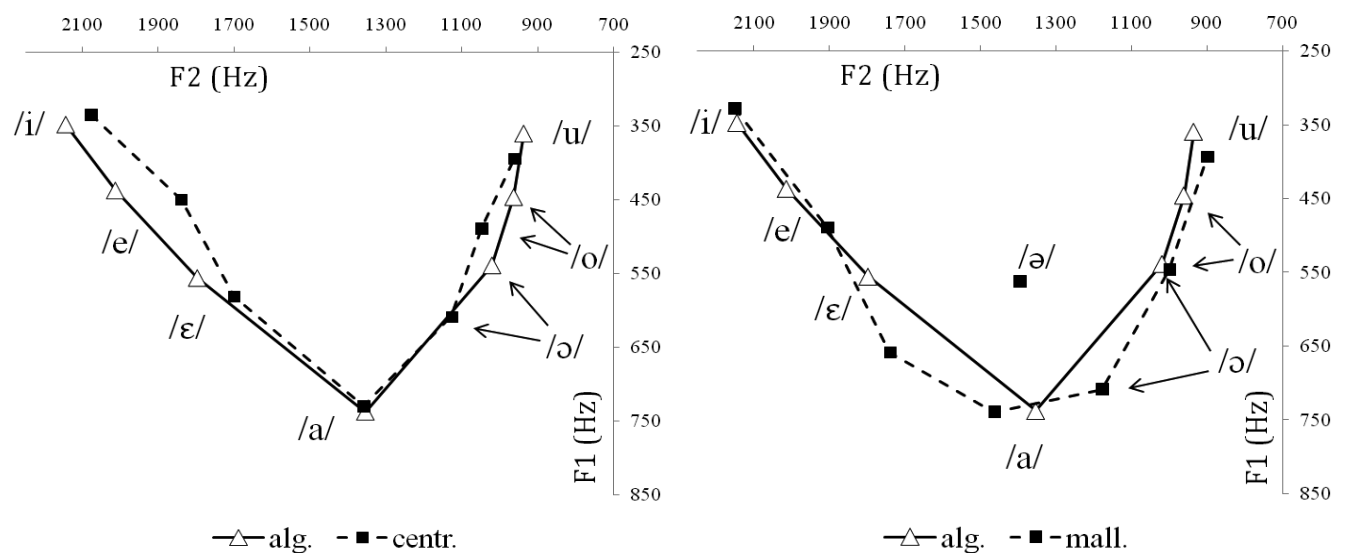

$\begin{array}{cccccccc}2100 & 1900 & 1700 & 1500 & 1300 & 1100 & 900 & 700 \\ 1 & 1 & 1 & 1 & 1 & 1 & +250\end{array}$

$\neg-$ alg. $-\square-$ mall.

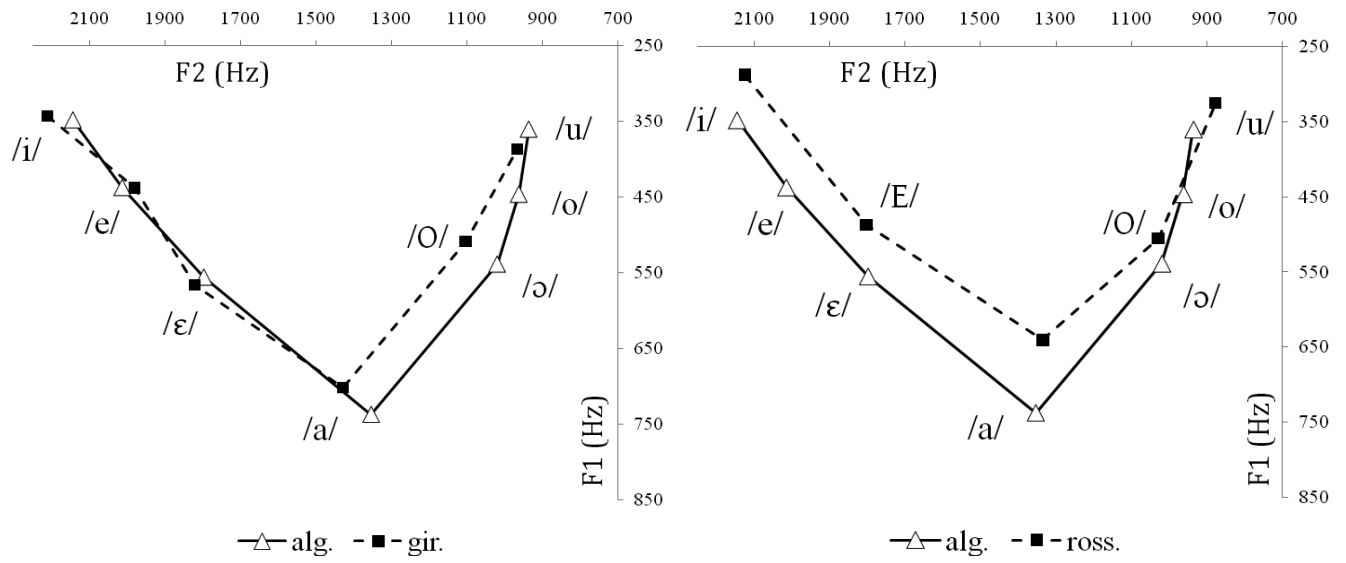


Francesc Ballone

Sobre la correcta interpretació dels fonemes vocàlics de l'alguerès: un estudi acústic

\section{APÈNDIX II}

Valors mitjans en $\mathrm{Hz}$ i Bark (B) de les vocals alguereses en funció del parlant (cinc parlants).

\begin{tabular}{|c|c|c|c|c|c|c|c|c|c|c|}
\hline \multicolumn{3}{|c|}{ PS } & \multicolumn{4}{|c|}{ SM } & \multicolumn{4}{|c|}{$\mathrm{PB}$} \\
\hline $\mathrm{F}_{2}$ & FI $(B)$ & $\mathrm{F}_{2}(\mathrm{~B})$ & $\mathrm{F}_{\mathrm{I}}$ & $\mathrm{F}_{2}$ & FI $(B)$ & $\mathrm{F}_{2}(\mathrm{~B})$ & $\mathrm{F}_{\mathrm{I}}$ & $\mathrm{F}_{2}$ & FI (B) & $\mathrm{F}_{2}(\mathrm{~B})$ \\
\hline 2265 & 3,43 & $\mathrm{I} 3,84$ & 350 & 1950 & 3,53 & $\mathrm{I} 2,84$ & 360 & 2180 & 3,63 & 13,59 \\
\hline 2188 & 4,32 & $\mathrm{I} 3,6 \mathrm{I}$ & $44 \mathrm{I}$ & 1825 & 4,39 & $\mathrm{I} 2,4 \mathrm{O}$ & $43 \mathrm{I}$ & 2050 & 4,30 & $\mathrm{I} 3, \mathrm{I} 8$ \\
\hline 1929 & 5,23 & $\mathrm{I} 2,77$ & 556 & I67I & 5,39 & $\mathrm{II}, 8 \mathrm{I}$ & 566 & I8I8 & 5,48 & $\mathrm{I} 2,37$ \\
\hline 1462 & 7,26 & 10,92 & 653 & I2I7 & 6,17 & 9,74 & 773 & I393 & 7,05 & IO,6I \\
\hline IO42 & 5,13 & 8,78 & 537 & IOI7 & 5,24 & 8,63 & $54 \mathrm{I}$ & 965 & 5,27 & 8,32 \\
\hline 992 & 4,44 & 8,48 & $45 \mathrm{I}$ & 953 & 4,49 & 8,24 & 440 & 923 & 4,39 & 8,05 \\
\hline 986 & 3,56 & 8,44 & 353 & 885 & 3,56 & $7,8 \mathrm{I}$ & 357 & 903 & 3,60 & 7,93 \\
\hline
\end{tabular}

\begin{tabular}{|c|c|c|c|c|c|c|c|c|}
\hline & SS & & & & $\mathrm{AC}$ & & & \\
\hline & $F_{I}$ & $\mathrm{~F}_{2}$ & $F_{I}(B)$ & $\mathrm{F}_{2}(\mathrm{~B})$ & $\mathrm{F}_{\mathrm{I}}$ & $\mathrm{F}_{2}$ & $\mathrm{~F}_{\mathrm{I}}(\mathrm{B})$ & $F_{2}(B)$ \\
\hline /i/ & 355 & 2185 & 3,58 & 13,60 & 334 & 2145 & 3,37 & $\mathrm{I} 3,48$ \\
\hline le/ & 460 & 2008 & 4,57 & $\mathrm{I} 3, \mathrm{O} 4$ & $42 \mathrm{I}$ & $200 \mathrm{I}$ & $4,2 \mathrm{I}$ & I3,OI \\
\hline $\mid \varepsilon /$ & 574 & 1803 & 5,54 & $\mathrm{I} 2,32$ & 546 & 1768 & 5,31 & $\mathrm{I} 2, \mathrm{I} 8$ \\
\hline la/ & 769 & I33I & 7,02 & $\mathrm{IO}, 3 \mathrm{I}$ & 689 & I364 & 6,44 & IO, 47 \\
\hline $10 /$ & 560 & 998 & 5,43 & 8,52 & $53 \mathrm{I}$ & 1075 & 5,19 & 8,97 \\
\hline /o/ & 450 & 943 & 4,48 & $8, \mathrm{I} 8$ & 443 & 999 & $4,4 \mathrm{I}$ & 8,52 \\
\hline$/ \mathrm{u} /$ & 373 & $9 \mathrm{I} 2$ & 3,76 & 7,98 & 363 & 992 & 3,66 & 8,48 \\
\hline
\end{tabular}

